\title{
Allergic Bronchopulmonary Aspergillosis Caused by Aspergillus terreus Presenting Lobar Collapse
}

\author{
Yoshiaki Nakahara, Osamu Katoh, Hozumi Yamada, Ikuo Sumida* and Motosuke Hanada* \\ A case of allergic bronchopulmonary aspergillosis (ABPA) is described which presents left \\ upper lobe collapse caused by Aspergillus terreus, an organism rarely found in ABPA. It is \\ unusual for initial radiographic findings of ABPA to include extensive collapse. \\ (Internal Medicine 31: 140-142, 1992)
}

Key words: ABPA, mucoid impaction, massive atelectasis

\section{Introduction}

Allergic bronchopulmonary aspergillosis (ABPA), a disease caused by hypersensitivity reactions to aspergillus organisms, is characterized by bronchial asthma, pulmonary opacities and eosinophilia $(1,2)$. Although pulmonary collapse is one of the features of ABPA, it is extremely uncommon case for the patient to have extensive collapse $(3,4)$. In the present patient, collapse of the left upper lobe due to ABPA was presented as part of the initial radiographic findings, and in addition, the causative organism was Aspergillus terreus, which is rarely encountered in $\mathrm{ABPA}(5,6)$.

\section{Case Report}

A 71-yr-old woman had been well until November 1988, when she had a productive cough, exertional dyspnea and intermittent wheezes. Her chest roentgenogram showed progressive collapse of the left upper lobe; she had a high fever despite treatment with antibiotics. She was admitted to our hospital on December 19, 1988. She was a non-smoker and had no clinical history of atopy or previous chest disease. On physical examination, breath sounds were decreased at the left anterior lung field and rales were not audible. The laboratory findings on admission are shown in Table 1. Hemoglobin value was $10.1 \mathrm{~g} / \mathrm{dl}$ and white blood cell count was $9,060 / \mathrm{mm}^{3}$ with $1,993 / \mathrm{mm}^{3}$ of eosinophils. Erythrocyte sedimentation rate was $85 \mathrm{~mm}$ in $1 \mathrm{~h}$. Cell analysis in the bone marrow appeared to be normal except for the eosinophils at $15 \%$. Serum $\mathrm{IgE}$ level was elevated to $15,700 \mathrm{IU} / \mathrm{ml}$ and radioallergosorbent test (RAST) for Aspergillus fumigatus (A. fumigatus) was positive. Intradermal skin test with $A$. fumigatus antigen gave a strongly positive immediate reaction but no late reaction was observed at 4 to $6 \mathrm{~h}$, and precipitins against Aspergillus terreus (A. terreus), assayed by Ouchterlony double-diffusion gel technique (9), were detected, but not against $A$. fumigatus. Repeat sputum cultures grew $A$. terreus. The chest roentgenogram on admission showed complete collapse of the left upper lobe (Fig. 1). Bronchoscopy demonstrated mucoid impaction which plugged the orifice of the left upper lobe bronchus (Fig. 2). A. terreus was cultured from the bronchial aspirates containing eosinophils and sputum. Therefore, it was highly likely that this organism caused the ABPA in the present patient. A chest CT showed proximal bronchiectatic change of the upper lobe bronchus after treatment with physiotherapy and aspiration by bronchoscopy. She was treated with a short course of prednisolone $(30 \mathrm{mg} /$ day). Three weeks thereafter her chest roentgenogram cleared completely and she has remained well.

\section{Discussion}

ABPA is an example of asthmatic pulmonary eosinophilia. This condition was first described in 1952 by Hinson et al (1). A variety of serologic, radiologic and clinical observations had been reported before 1977 , when the criteria for the diagnosis of ABPA were established by Rosenberg and co-workers (2). The primary criteria include the following: episodic bronchial obstruction (asthma), eosinophilia, positive immediate skin

From Department of Internal Medicine, Saga Medical School, Saga, *Department of Internal Mẹdicine, Karatsu Red Cross Hospital, Karatsu Received for publication September 21, 1990; Accepted for publication May 30, 1991

Reprint requests should be addressed to Yoshiaki Nakahara, MD, Department of Internal Medicine, Saga Medical Hospital, 5-1-1 Nabeshima, Saga 849 , Japan 
Allergic Bronchopulmonary Aspergillosis

Table 1. Laboratory Findings

\begin{tabular}{|c|c|c|c|}
\hline Peripheral blood & & $\mathrm{Na}$ & $140 \mathrm{mEq} / 1$ \\
\hline $\mathrm{RBC}$ & $344 \times 10^{4} / \mathrm{mm}^{3}$ & $\mathrm{~K}$ & $4.0 \mathrm{mEq} / 1$ \\
\hline $\mathrm{Hb}$ & $10.1 \mathrm{~g} / \mathrm{dl}$ & $\mathrm{Cl}$ & $104 \mathrm{mEq} / \mathrm{l}$ \\
\hline $\mathrm{Ht}$ & $31.3 \%$ & & \\
\hline WBC & $9,060 \times 10^{3} / \mathrm{mm}^{3}$ & ESR & $80 \mathrm{~mm} / \mathrm{h}$ \\
\hline Stab & $6 \%$ & Serology & \\
\hline Seg & $45 \%$ & CRP & $8.3 \mathrm{mg} / \mathrm{dl}$ \\
\hline Lymph. & $23 \%$ & RA & $(+)$ \\
\hline Mono. & $4 \%$ & ASLO & $(-)$ \\
\hline Eosino. & $22 \%$ & ANA & $<10 x$ \\
\hline \multirow[t]{2}{*}{ Plt } & $27.8 \times 10^{4} / \mathrm{mm}^{3}$ & $\mathrm{C}_{3}$ & $112 \mathrm{mg} / \mathrm{dl}$ \\
\hline & & $\mathrm{C}_{4}$ & $47.6 \mathrm{mg} / \mathrm{dl}$ \\
\hline Blood chemistry & & CH50 & $62.5 \mathrm{U} / \mathrm{ml}$ \\
\hline T.P. & $6.4 \mathrm{~g} / \mathrm{dl}$ & $\operatorname{IgE}$ & $15,700 \mathrm{U} / \mathrm{ml}$ \\
\hline $\mathrm{Alb}$ & $51.2 \%$ & \multicolumn{2}{|c|}{ RAST $A$. fumigatus 3.3PRU $/ \mathrm{ml}$} \\
\hline$\alpha_{1}$ & $4.5 \%$ & & \\
\hline$\alpha_{2}$ & $10.2 \%$ & Precipitins & \\
\hline$\beta$ & $11.1 \%$ & A. fumigatus & $(-)$ \\
\hline$\gamma$ & $22.9 \%$ & A. terreus & $(+)$ \\
\hline T.B. & $0.26 \mathrm{mg} / \mathrm{dl}$ & & \\
\hline GOT & $25 \mathrm{IU}$ & Skin test & \\
\hline GPT & $14 \mathrm{IU}$ & PPD $(48 h)$ & $2 \times 2 \mathrm{~mm}$ \\
\hline $\mathrm{LDH}$ & $482 \mathrm{IU}$ & A. fumigatus & $40 \times 30 \mathrm{~mm}$ \\
\hline Al-p & $152 \mathrm{IU}$ & $(15 \mathrm{~min})$ & \\
\hline $\mathrm{Ch}-\mathrm{E}$ & $0.62 \Delta \mathrm{PH}$ & & \\
\hline T.chol. & $165 \mathrm{mg} / \mathrm{dl}$ & Sputa (bronchoschopi & exam.) \\
\hline ZTT & $9.3 \mathrm{IU}$ & Culture & \\
\hline BUN & $12.6 \mathrm{mg} / \mathrm{dl}$ & Bacteria & $(-)$ \\
\hline $\mathrm{Cr}$ & $0.65 \mathrm{mg} / \mathrm{dl}$ & Acid-fast bacill & $(-)$ \\
\hline UA & $2.6 \mathrm{mg} / \mathrm{dl}$ & A. terreus & $(+)$ \\
\hline FBS & $100 \mathrm{mg} / \mathrm{dI}$ & Cytology & class II \\
\hline
\end{tabular}

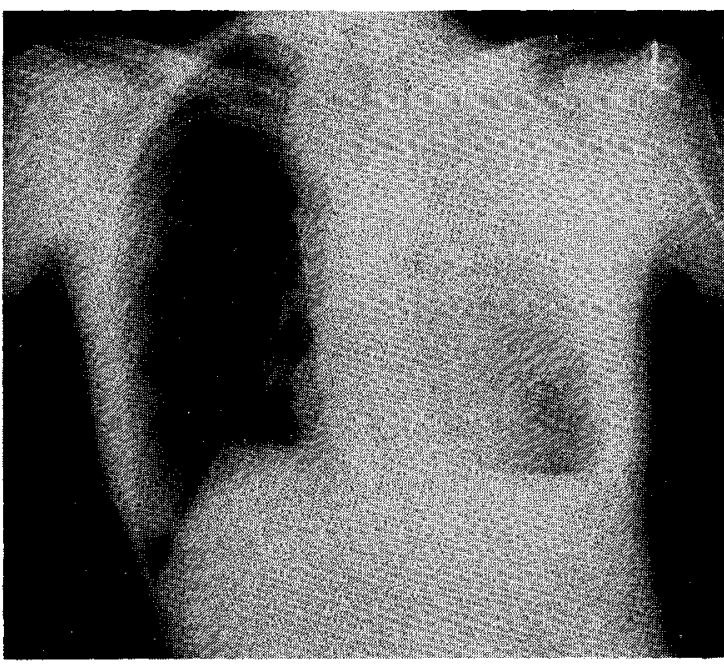

Fig. 1. Chest X-ray film on admission showing left upper lobe collapse.

reactivity, serum precipitating antibodies, elevated serum $\mathrm{IgE}$, history of pulmonary infiltrates and central bronchiectasis. The secondary criteria include: Aspergilluspositive sputum culture, history of expectrating brown plugs or flecks, Arthus (late) skin reactivity. The patient in this report satisfied six of the seven primary criteria and two of the three secondary criteria (2). In addition,

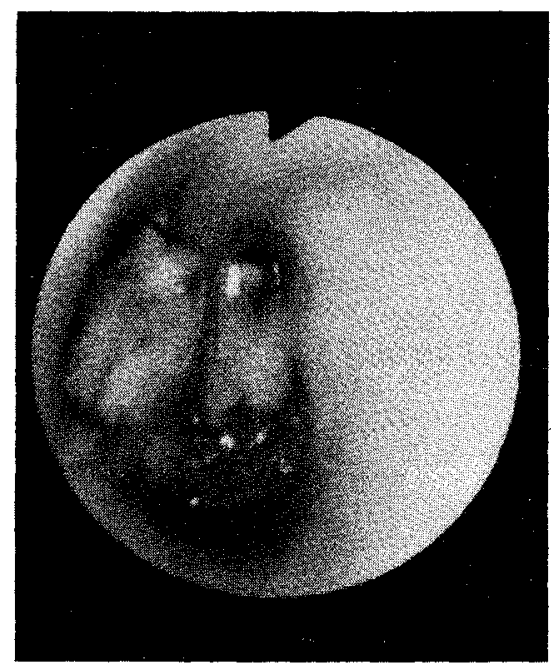

Fig. 2. Endobronchial photographs revealing mucoid impaction plugging the orifice of the left upper lobe bronchus.

the lesion seen on the chest roentgenogram as well as clinical symptoms were imporved by the steroid therapy. Based on these clinical manifestations, the diagnosis of ABPA in this case was justified. Remarkable was the fact that culture of the patient's bronchial aspirates and sputum grew $A$. terreus, which had only been regarded 


\section{Nakahara et al}

as a contaminant in the past. Indeed only a few cases of ABPA with $A$. terreus have been reported in the literature $(5,6)$.

In this case, $A$. fumigatus antigen gave a strongly positive immediate reaction but no late reaction at $4-6 \mathrm{~h}$, and precipitins for $A$. fumigatus were negative. Laham et al (5) reported a case of ABPA caused by $A$. terreus, in which skin tests with $A$. fumigatus gave a positive immediate reaction, but no late reaction, and precipitins against $A$. terreus, but not against $A$. fumigatus were detected in serum. Therefore, we prepared $A$. terreus and $A$. fumigatus antigens adjusted to the optimal protein content, according to the methods of Laham et al, and assayed the present patient's serum for precipitins by the double-diffusion gel technique of Ouchterlony (9). And, as a result, precipitins were positive against $A$. terreus antigen but not $A$. fumigatus. Therefore, there seems to be no doubt that $A$. terreus is the causative organism in this case of ABPA.

$A$ radiographic feature commonly found in $A B P A$ is transient migrating infiltrate, which may be patchy, triangular, or oblong, and it usually appears in the upper lobes. Such infiltrates consist of subsegmental atelectasis due to mucoid impaction and parenchymal infiltration. Proximal bronchiectasis or secretions in the damaged bronchus may contribute to other radiographic findings such as toothpaste shadow, glove-finger shadow, tramline shadow, and air-fluid levels $(7,8)$. Although collapse is one of the radiographic findings caused by ABPA, it is usually presented as subsegmental atelectasis secondary to mucoid impaction. In this patient, the chest roentgenogram showed left upper lobe collapse; bronchoscopy revealed mucoid impaction of the left upper bronchus with the more distal bronchi filled with inspissated mucus. These findings are compatible with the features of ABPA, but it is unusual that such extensive collapse as was encountered in the present patient's left upper lobe is found in the initial radiographic findings of $\operatorname{ABPA}(3,4)$. It recommended that ABPA is included in the differential diagnosis of extensive pulmonary collapse.

\section{References}

1) Hinson KFW, Moon AJ, Plummer NS. Bronchopulmonary aspergillosis. Thorax 7: 317, 1952.

2) Rosenberg $M$, Patterson R, Mintzer $R$, et al. Clinical and immunologic criteria for the diagnosis of allergic bronchopulmonary aspergillosis. Ann Intern Med 86: 405, 1977.

3) Berkin KE, Vernon DRH, Kerr JW. Lung collapse caused by allergic bronchopulmonary aspergillosis in non-asthmatic patients. Br Med J 285: 552, 1982.

4) Fraser RG, Pare JAP, Pare PD, Fraser RS, Genereux GP. Hypersensitivity aspergillosis. in: Diagnosis of Diseases of the Chest, 3rd ed., WB Saunders Co, Philadelphia, 1989, p. 993.

5) Laham MN, Allen RC, Greene JC. Allergic bronchopulmonary aspergillosis caused by Aspergillus terreus: Specific lymphocyte sensitization and antigen-directed serum opsonic activity. Ann Allergy 46: 74, 1981.

6) Laham MN, Carpenter JL. Aspergillus terreus, a pathogen capable of causing infective endocarditis, pulmonary mycetoma, and allergic bronchopulmonary aspergillosis. Am Rev Respir Dis 125: 769, 1982.

7) Ricketti AJ, Mintzer RA. Allergic bronchopulmonary aspergillosis. Chest 86: 773, 1984.

8) Mintzer RA, Rogers LF, Kruglik GD, Rosenberg M, Neiman HL, Patterson $M$. The spectrum of radiologic findings in allergic bronchopulmonary aspergillosis. Radiology 127: 301, 1978.

9) Ouchterlony Ö. Immunological Methods. Gel-Diffusion Techniques, Ackroyd, JF, Ed. Blackwell, Oxford, 1964. 